\title{
Optimization of ionic liquid-based microwave-assisted extraction on brazilin levels from sappan wood and its dipeptidyl peptidase IV inhibition activity
}

\author{
Islamudin Ahmad ${ }^{1}$ (D), Erwi Putri Setyaningsih², Ayun Erwina Arifianti ${ }^{3}$, Fadlina Chany Saputri ${ }^{4}$, Abdul Mun'im², ${ }^{2 *}$ \\ ${ }^{1}$ Department of Pharmaceutical Sciences, Faculty of Pharmacy, Universitas Mulawarman, Samarinda, 75119 East Kalimantan, Indonesia \\ ${ }^{2}$ Graduate Program of Herbal Medicine, Faculty of Pharmacy, Universitas Indonesia, Depok, 16424 West Java, Indonesia \\ ${ }^{3}$ Department of Pharmaceutical Technology, Faculty of Pharmacy, Universitas Indonesia, Depok, 16424 West Java, Indonesia \\ ${ }^{4}$ Laboratory of Pharmacology, Faculty of Pharmacy, Universitas Indonesia, Depok, 16424 West Java, Indonesia \\ ${ }^{5}$ Department of Pharmacognosy-Phytochemistry, Faculty of Pharmacy, Universitas Indonesia, Depok, 16424 West Java, Indonesia
}

\begin{tabular}{l}
\hline ARTICLE INFO \\
\hline Received on: 09/03/2021 \\
Accepted on: 28/05/2021 \\
Available online: 05/07/2021 \\
\\
\hline Key words: \\
Brazilin, dipeptidyl \\
peptidase IV, ionic liquid- \\
based microwave-assisted \\
extraction, response surface \\
methodology, sappan wood \\
(Caesalpinia sappan).
\end{tabular}

\begin{abstract}
To elevate brazilin levels from sappan wood (Caesalpinia sappan) using the optimized ionic liquid-based microwave-assisted extraction (IL-MAE) method and to evaluate its dipeptidyl peptidase IV (DPP-IV) inhibition activity. According to the preoptimization results, the IL-MAE method condition's optimization was carried out using response surface methodology with the Box-Behnken design. Brazilin levels were determined by the high performance liquid chromatography (HPLC) gradient method $(0.3 \%$ acetic acid in water and acetonitrile). A DPP-IV inhibition activity assay was then conducted using the DPP-IV-Glo ${ }^{\mathrm{TM}}$ kit and determined using Glomax (Promega, Madison, WI) with an excitation of 350-360 nm and an emission of $450-465 \mathrm{~nm}$. The most optimized extraction condition was $1.5 \mathrm{~mol} / 1$ 1-butyl-3-methyl imidazolium bromide ([BMIM]Br), 1:20 g/ml solid-to-liquid ratio, and 9 minutes of extraction time. HPLC analysis of sappan extract showed brazilin levels of 807.56-948.12 mg/g extract. Sappan extract gives the in vitro inhibitory value of DPP-IV activity of $>90 \%$. The inhibition concentration of $50 \%$ value was obtained including $9.37 \mu \mathrm{g} / \mathrm{ml}$ (sitagliptin), $11.7 \mu \mathrm{g} / \mathrm{ml}$ (brazilin standard), $16.35 \mu \mathrm{g} / \mathrm{ml}$ (extract sample), and $22.15 \mu \mathrm{g} / \mathrm{ml}$ (tannin removal sample). In the present study, imidazolium basic IL-MAE was optimized and first applied to elevate the brazilin levels from sappan wood. Thus, this is an optimum extraction condition for elevating sappan wood's brazilin levels rapidly, efficiently, quickly, and environmentally friendly.
\end{abstract}

\section{INTRODUCTION}

The application of green chemistry on the selection of solvents has increased to explore the content and potential effect of active compounds from natural sources. Ionic liquid (IL) was discovered as an option to replace organic solvents (Espino et al., 2016). IL is a pure salt compound containing ionic components (cation and anion), which melts at a temperature below $100^{\circ} \mathrm{C}$ (Tan et al., 2016). IL can be applied to separation techniques because of its physical and chemical properties, not readily volatile, good stability, viscosity, solubility, and good extraction ability

\section{"Corresponding Author}

Abdul Munim, Universitas Indonesia, Depok, Indonesia.

E-mail:munimabdoel@gmail.com of different organic compounds and easy to control compared to conventional solvents (Chen et al., 2014). Some previous studies have carried out sappan extraction using conventional extraction and solvent methods. Ethanol and methanol were used as conventional solvents in sappan extraction. Still, the extraction has several disadvantages: the number of solvents used, long extraction times, and not environmentally friendly (Du et al., 2007, 2009).

Microwave-assisted extraction (MAE) is widely used to replace conventional extraction methods used to use volatile organic solvents such as methanol, ethanol, hexane, and ethyl acetate. The advantages of MAE compared to conventional extraction methods are easy to use, fast, efficient, effective, good selectivity, and inexpensive (Ballard et al., 2010; Du et al., 2007). The application of the microwave extraction method has been 
proven to be the most optimum method for extracting red dye from sappan wood for $0.747 \mathrm{~g}$; the results are higher than conventional extraction methods of $0.660 \mathrm{~g}$ (Badami et al., 2014).

IL-based microwave-assisted extraction (IL-MAE) method is a nonconventional extraction used in green solventbased extraction processes (Ahmad et al., 2018). Some studies have reported that applying the IL-MAE method to obtain the optimal target secondary metabolite included flavonoid extraction from Cyclea barbata Miers. (Ahmad et al., 2020b), polyphenols extraction from Peperomia pellucida (L.) Kunth (Ahmad et al., 2017), orientin and vitexin extraction of Trollius chinensis (Chen et al., 2017), extractions of flavonoid of Scutellaria baicalensis Georgi (Zhang et al., 2015), pigeon pea leaves (Wei et al., 2012), Bauhinia championii (Xu et al., 2012), oxyresveratrol extraction of Morus alba roots (Fadhila et al., 2018), extractions of transresveratrol of Gnetum gnemon (Ayuningtyas et al., 2017), and also the extraction of quercetin and kaempferol from Toona sinensis and Rosa sinensis (Liu et al., 2013).

According to the screening of ten Indonesian plant ethanolic extracts previously conducted, the ethanolic extract of Caesalpinia sappan had the best dipeptidyl peptidase IV (DPPIV) inhibitory activity than other plant extracts' activity equivalent with sitagliptin. Brazilin is the main component in C. sappan. The DPP-IV inhibition test by brazilin standard solutions showed significant inhibitory activity. Sappan wood was chosen as the sample in this study, and extraction results using conventional methods (maceration) were used for comparison (Setyaningsih et al., 2019).

Based on the literature search, no research has been found on IL's use combined with MAE as a solvent and extraction method. Based on this description, we are interested in researching the application of IL-MAE methods to increase brazilin levels in sappan extract, which have a mechanism of action against DPP-IV inhibitors as an alternative treatment for diabetes.

\section{MATERIALS AND METHODS}

\section{Materials}

The materials used in this study, including sappan wood (C. sappan), were purchased from Bogor Botanical Garden and identified $\mathrm{n}$ Indonesia Institute of Sciences (LIPI) Bogor. 1-butyl-3 methyl imidazolium bromide ([BMIM]Br), 1-butyl-3-methyl imidazolium tetrafluoroborate ([BIMI] $\left.\mathrm{BF}_{4}\right)$, and 1-butyl-3-methyl imidazolium hexafluorophosphate ([BMIM] $\mathrm{PF}_{6}$ were purchased from Shanghai Chen Jie Chemicals, China; brazilin standard was purchased from MP Biomedicals, France; DPP-IV enzyme assay kit was purchased from Cayman Chem, USA; $\mathrm{NaHCO}_{3}, \mathrm{~K}_{2} \mathrm{HPO}_{4}$, $\mathrm{KH}_{2} \mathrm{PO}_{4}$ ethanol, double-distilled water, ethyl acetate, methanol, and acetonitrile HPLC grade were purchased from Brataco Chemika, Indonesia.

\section{Extraction process}

According to the literature, the extraction process was carried out (Ahmad et al., 2017, 2020b). Briefly, $1 \mathrm{~g}$ of each simplicia was extracted with MAE's different conditions using a 540-watt microwave. The IL solution with a different concentration and solid-to-liquid ratio was added into a round-bottomed flask and extracted on the microwave with varying extraction time variations. After the extraction, the extract was filtered and added with ethyl acetate and salt, then vortexed for 5 minutes, and centrifuged at 3,000 rpm for 15 minutes until two phases were formed. The supernatant (ethyl acetate phase) was taken and dried by aerating in the open air to evaporate the ethyl acetate.

\section{Selection of IL solvents}

The selection of IL solvents was conducted qualitatively by comparing the colors formed in each standard solution. 10 $\mathrm{mg}$ of brazilin standard was dissolved in $10 \mathrm{ml}$ of different IL solvents. The IL solvents tested were $[\mathrm{BMIM}] \mathrm{Br},[\mathrm{BMIM}] \mathrm{BF}_{4}$, and [BMIM] $\mathrm{PF}_{6}$ with a concentration of $2 \mathrm{~mol} / \mathrm{l}$. The samples were vortexed until wholly dissolved and then the color formed in each standard solution was compared. The more concentrated color of the standard solution is assumed by brazilin dissolves optimally. IL, which can dissolve the standard more optimally, was chosen as the solvent used in this study.

\section{Separation of brazilin from IL solution}

$10 \mathrm{ml}$ of each extract was added with $10 \mathrm{ml}$ ethyl acetate and some variations of salt $\left(\mathrm{NaHCO}_{3}, \mathrm{~K}_{2} \mathrm{HPO}_{4}\right.$, and $\left.\mathrm{KH}_{2} \mathrm{PO}_{4}\right)$ in each concentration $0.01,0.1$, and $0.5 \mathrm{M}$ and then vortexed and centrifuged until two phases were formed. The supernatant was taken for analyzing the brazilin in the extract using thin layer chromatography (TLC) densitometry. Analysis with the same procedure of the sample without salt needs to be conducted as a control.

\section{TLC-densitometry analysis}

As much as $100 \mathrm{ppm}$ of the sample and brazilin standard were spotted on TLC silica gel aluminum plates using a microcapillary tube of $5 \mu$ l. The mobile phase consisted of ethyl acetate:toluene:acetic acid glacial (7:3:1). The chromatogram run length was $8 \mathrm{~cm}$ through the glass chamber saturated by the mobile phase. Subsequently, the TLC plate was air-dried. The scanning was carried out with Camag TLC Scanner III in absorbance length at $366 \mathrm{~nm}$ and operated by winCATS software. The brazilin spot in a sample was confirmed by comparing the spectrum and the standard spot's Rf value (Badami et al., 2014). The concentration of brazilin in the sample is calculated using the following equation:

$$
\mathrm{C}_{\text {brazilin }}=\frac{\text { sample area }}{\text { standard area }} \times \frac{\text { standard volume spotted }}{\text { sample volume spotted }} \times \mathrm{C}_{\text {standar }}
$$

\section{Preoptimization of IL concentration}

Different concentrations of $0.5,1,1.5$, and $2 \mathrm{~mol} / \mathrm{l}$ [BMIM]Br were optimized to obtain optimum extraction conditions. $1 \mathrm{~g}$ of simplicia was added with $15 \mathrm{ml}$ [BMIM]Br of different concentrations. The extract was added with $10 \mathrm{ml}$ of ethyl acetate and $10 \mathrm{ml} \mathrm{K}_{2} \mathrm{HPO}_{4}$, vortexed for 5 minutes, and centrifuged at 3,000 rpm for 15 minutes until two phases were formed. The supernatant was taken and dried in the open air for analysis using HPLC (Ahmad et al., 2018).

\section{Preoptimization of extraction time}

Extraction times of 5, 7, and 9 minutes were optimized to obtain optimum extraction conditions. $1 \mathrm{~g}$ of simplicia was added with $15 \mathrm{ml}$ [BMIM] $\mathrm{Br} 1 \mathrm{~mol} / \mathrm{l}$. The extract was added with 
$10 \mathrm{ml}$ of ethyl acetate and $10 \mathrm{ml} \mathrm{K}_{2} \mathrm{HPO}_{4}$, vortexed for 5 minutes, and centrifuged at $3,000 \mathrm{rpm}$ for 15 minutes until two phases were formed. The supernatant was taken and dried in the open air for analysis using HPLC (Ahmad et al., 2018).

\section{Optimization of IL-MAE by response surface methodology (RSM)}

Optimization of the IL-MAE was carried out using RSM via licensed Design Expert version 12 software (Statease Inc., Minneapolis, MN), which can analyze the interaction between processes and factors extraction condition against response (yield, brazilin levels, and DPP-IV inhibition activity percentage). The independent factors are IL concentration $(0.5,1$, and $2 \mathrm{~mol} / \mathrm{l})$, solid-to-liquid ratio (1:10, 1:15, and $1: 20 \mathrm{~g} / \mathrm{ml})$, extraction time (5, 7 , and 9 minutes), and constant power of 540 watts. The dependent factors are brazilin levels (\%), yield (\%), and inhibitory activity $(\%)$ in 17 runs.

\section{Yield of sappan extract}

The yield calculation obtained after the extraction process was calculated using the following equation:

Yield $(\%)=\frac{\text { Brazilin amount in extract }(\mathrm{g})}{\text { Sappan wood sample amount }(\mathrm{g})} \times 100 \%$

\section{DPP-IV activity assay}

The DPP-IV-Glo ${ }^{\mathrm{TM}}$ assay was used to measures DPPIV inhibitor activity. It was determined using Glomax (Promega, Madison, WI) with an excitation wavelength of 350-360 nm and an emission wavelength of 450-465 $\mathrm{nm}$ (Ahmad et al., 2020a) Each sample were reconstituted in $80 \%$ ethanol to a final concentration of 1,000 ppm. The assay used a 96-well microplate, and the reaction per well was included. $10 \mu \mathrm{l}$ of the test sample was mixed with $30 \mu 1$ of assay buffer solution and $10 \mu 1$ of DPP-IV solution. Enzyme control was prepared using $80 \%$ ethanol instead of the sample. Inhibitor control (Sitagliptin) was designed using an inhibitor solution in place of the sample. Subsequently, $50 \mu 1$ of H-Gly-Pro-AMC substrate was added; then the microplate was incubated at $37^{\circ} \mathrm{C}$ for 30 minutes. Each test sample was analyzed in triplicate. Percent inhibition was calculated using the following formula in the equation:

$\%$ Inhibition $=\left(\frac{\text { Initial Activity -Inhibitor }}{\text { Initial Activity }}\right) \times 100 \%$

\section{Tannin elimination}

A gelatin solution (1\%) was added to the test filtrate. The flask was shaken at $100 \mathrm{rpm}$ for 10 minutes at $25^{\circ} \mathrm{C}$. The supernatant was dried in a water bath and oven vacuum and then dissolved with $80 \%$ ethanol to ensure the tannin effect DPP-IV inhibitory activity of the extract.

\section{Determination of brazilin in the extract by HPLC analysis}

Quantification of brazilin in the extract was carried out using the HPLC gradient method. Each extract solution was dissolved in $80 \%$ ethanol until $100 \mathrm{ppm}$ was reached and then filtered with micropore $0.45 \mu \mathrm{m}$. The injected volume was 20 $\mu 1$, and a flow rate was $1.0 \mathrm{ml} /$ minutes. Determination of brazilin
Table 1. Mobile phase composition.

\begin{tabular}{ccc}
\hline Time & $\mathbf{0 . 3} \%$ acetic acid $(\mathbf{m l})$ & Acetonitrile $(\mathbf{m l})$ \\
\hline 0 & 85.5 & 14.5 \\
12 & 85.5 & 14.5 \\
15 & 5 & 95 \\
18 & 5 & 95 \\
19 & 85.5 & 14.5 \\
25 & 85.5 & 14.5 \\
\hline
\end{tabular}

refers to the previous research method using $0.3 \%$ acetic acid in water:acetonitrile as the mobile phase with adjusted composition as in Table 1.

\section{RESULTS AND DISCUSSION}

\section{Selection criteria of factors and pre-optimization for extraction process}

Three types of hydrophilic solvents, namely [BMIM] $\mathrm{Br},[\mathrm{BMIM}] \mathrm{BF}_{4},[\mathrm{BMIM}] \mathrm{PF}_{6}$, were compared to choose the appropriate kind of IL solvent and have better efficiency in extracting active sappan compounds. The selection of solvents was carried out qualitatively using a $100 \mathrm{ppm}$ brazilin standard. The color of the brazilin standard on [BMIM]Br was more concentrated than other solvents. So, [BMIM]Br was chosen as an extraction solvent. Cation on [BMIM]Br, [BMIM]BF ${ }_{4}$, and $[\mathrm{BIM}] \mathrm{PF}_{6}$ was 1-butyl-3-methylimidazolium, which affects the extraction of brazilin. The presence of ionic bonds caused this and hydrogen bonds between the cations of imidazolium and brazilin increased the solubility of brazilin in the solvent (Putri et al., 2017). The color of the brazilin standard in [BMIM]Br was more concentrated due to bromide anions $\left(\mathrm{Br}^{-}\right)$, which can make ionic solutions more acidic than other anions (Anderson et al., 2002). The weak acidic ionic solution provides an advantage in extracting brazilin (Xia et al., 2017).

Brazilin is a hydrophobic target compound, so it will be easier to extract it again with organic solvents from hydrophobic IL. IL is a nonvolatile solvent, so organic solvents such as dichloromethane, chloroform, n-butanol, isoamyl alcohol, diethyl ether, petroleum ether, ethyl acetate, and n-hexane are needed to separate IL solvents with target compounds (Settharaksa et al., 2017). Ethyl acetate was chosen to separate the IL from the target compound because it has the highest efficiency compared to other organic solvents to re-extract phenolic compounds.

Some types of salt used are selected to be optimized based on Mai et al.'s (2014) experiments. Brazilin was successfully separated from the IL phase using several salt types at various concentrations measured semi-quantitatively, using the densitometry TLC method.

IL is a chaotropic salt. The interaction between IL and salt will be a salting out process. Salting out occurs because of competition between salt and IL to bind water. The added salt causes the attracted water molecules to bind and deposit unwanted impurities to facilitate the process of recalling target compounds from IL using organic solvents (Nirmal et al., 2015).

Adding salt causes a disruption of intermolecular hydrogen bonds, which causes the cell wall to dissolve and release 
target compounds (Nirmal et al., 2015). According to previous research, salt is known to help optimize the separation of target compounds from IL solvents and improve extraction results. This is indicated by the increased yield of the oxiresveratrol compounds by adding $\mathrm{KH}_{2} \mathrm{PO}_{4}$ salt compared to without the addition of salt (Tan et al., 2016).

In addition, based on our previous studies (Ahmad et al., 2017, 2018, 2020b; Ayuningtyas et al., 2017; Putri et al., 2017), other factors such as liquid-to-solid ratio and extraction time significantly affect the optimization process of the target compound's extraction conditions. These two factors were chosen because they adjust to the conditions of the equipment in the lab, where these factors can be adjusted in such a way to obtain the maximum target compound. Nevertheless, to get the ideal conditions, it is necessary to preoptimize.

\section{Optimization IL-MAE by RSM}

Optimization of IL-MAE was carried out using RSM with Box-Behnken design (three factors and three levels) on the same response including the yield value $(\%, w / w)$, brazilin levels $(\mathrm{mg} / \mathrm{g})$, and DPP-IV inhibitory activity (\%). The independent factors include [BMIM] Br concentration $(0.5,1$, and $1.5 \mathrm{~mol} / \mathrm{l})$, solid-to-liquid ratio $(1: 10,1: 15$, and $1: 20 \mathrm{~g} / \mathrm{ml})$, and extraction time $(5,7$, and 9 minutes) as can be seen in Table 2 . In the 14th run with [BMIM]Br concentration of $1 \mathrm{~mol} / \mathrm{l}$, the solid-to-liquid ratio of $1: 20 \mathrm{~g} / \mathrm{ml}$ and an extraction time of 9 minutes showed the highest obtained response, according to the obtained RSM analysis results using Design Expert v12 software. Figure 1 shows the three dimensions of response surface plots for interaction between responses and extraction condition factors. The contour of response surface plots shows that the factors used still need to be redesigned to obtain a better correlation, even though the optimization results are valid according to the statistical parameters presented in some tables in this manuscript (Settharaksa et. al., 2017). Ethyl acetate was chosen to separate the IL from the target compound because it has the highest efficiency compared to other organic solvents to re-extract target compound.

Based on the RSM analysis, the regression model of each response was obtained that predicts the response of yield value $(\%, w / w)$, brazilin levels $(\mathrm{mg} / \mathrm{g})$, and DPP-IV inhibitory activity (\%) with the following formula: Yield value $=0.3795-$ $0.225 X_{1}+0.1 X_{2}+0.0825 X_{3}+0.1250 X_{1} X_{3}-0.1613 X_{1}^{2}+0.3312 X_{3}^{2}$ $-0.0975 X_{1}^{2} X_{2}+0.4335 X_{1} X_{2}^{2}$ with $R^{2}=0.8046$; brazilin levels $=$ $815.35-55.85 X_{1}+15.27 X_{2}-13.29 X_{3}+14.1 X_{1} X_{3}+34.49 X_{2} X_{3}-$ $9.42 X_{1}^{2}+38 X_{2}^{2}+58.62 X_{2}-49.49 X_{1}^{2} X_{2}+59.44 X_{1} X_{2}^{2}$ with $R^{2}=$ 0.9911 ; DPP-IV inhibitory activity $=95.96-0.775 X_{1}+0.7775 X_{2}$ $+0.3638 X_{3}+175.69 X_{1} X_{2}+86.9 X_{1}^{2}+88 X_{2}^{2}-87 X_{3}^{2}+176.41$ $X_{1}^{2} X_{2}+177.34 X_{1} X_{2}^{2}$ with $R^{2}=0.99998$, where $X_{1}$ is [BMIM]Br concentration ( $\mathrm{mol} / \mathrm{l}) ; X_{2}$ is solid-to-liquid ratio $(\mathrm{g} / \mathrm{ml})$, and $X_{3}$ is extraction time (minute).

Table 3 shows an analysis of variance (ANOVA) of the yield value and the model $F$-value of 4.12 indicates that the model is significant. There is only a $3.08 \%$ chance that an $F$-value this large could occur due to noise. A $p$-value of 0.0308 (less than 0.05 ) indicates that model terms are significant. In this case, $X_{1}, X_{3}^{2}$, and $X_{1} X_{2}^{2}$ are significant model terms. The lack of fit $F$-value of 0.13 implies that the lack of fit is not significantly relative to the pure error.

Table 4 demonstrates the ANOVA result of brazilin levels and the model $F$-value of 67.19 means that the model is significant. A $p$-value of $<0.0001$ (less than 0.0500 ) indicates that the model terms are significant. In this model, $X_{1}, X_{2}, X_{3}, X_{1} X_{3}, X_{2} X_{3}$, $X_{2}^{2}, X_{3}^{2}, X_{1}^{2} X_{2}$, and $X_{1} X_{2}^{2}$ are significant model terms. The lack of fit $F$-value of 3.25 implies that the lack of fit is not significantly relative to the pure error.

Simultaneously, Table 5 revealed that the ANOVA results of DPP-IV inhibitory activity show the model $F$-value

Table 2. Extraction parameters based on RSM Box-Behnken design.

\begin{tabular}{|c|c|c|c|c|c|c|c|c|c|}
\hline \multirow[b]{2}{*}{ Run } & \multicolumn{3}{|c|}{ Extraction parameters } & \multicolumn{6}{|c|}{ Response } \\
\hline & $\begin{array}{c}(\mathrm{BMIM}) \mathrm{Br} \\
\text { concentration }(\mathrm{mol} / \mathrm{l})\end{array}$ & $\begin{array}{l}\text { Solid/liquid } \\
\text { ratio }(\mathrm{g} / \mathrm{ml})\end{array}$ & $\begin{array}{l}\text { Extraction time } \\
\text { (minute) }\end{array}$ & Yield (\%) & $\begin{array}{l}\text { Prediction } \\
\text { value }\end{array}$ & $\begin{array}{l}\text { Brazilin level } \\
(\mathrm{mg} / \mathrm{g})\end{array}$ & $\begin{array}{l}\text { Prediction } \\
\text { value }\end{array}$ & $\begin{array}{c}\text { Inhibitory } \\
\text { activity (\%) }\end{array}$ & $\begin{array}{l}\text { Prediction } \\
\text { value }\end{array}$ \\
\hline 1 & 1.0 & $1: 10$ & 9 & 0.59 & 0.67 & 848.61 & 873.64 & 95.9 & 95.11 \\
\hline 2 & 1.5 & $1: 10$ & 7 & 0.29 & 0.07 & 889.77 & 835.37 & 94.55 & 94.09 \\
\hline 3 & 1.0 & $1: 15$ & 7 & 0.8 & 0.39 & 809.37 & 815.35 & 95.08 & 95.95 \\
\hline 4 & 0.5 & $1: 10$ & 7 & 0.1 & 0.21 & 866.52 & 871.49 & 92.8 & 93.0 \\
\hline 5 & 1.5 & $1: 20$ & 7 & 0.3 & 0.19 & 805.28 & 800.30 & 93.56 & 93.35 \\
\hline 6 & 1.0 & $1: 15$ & 7 & 0.3 & 0.39 & 810.8 & 815.35 & 95.9 & 95.95 \\
\hline 7 & 1.0 & $1: 15$ & 7 & 0.29 & 0.39 & 814.11 & 815.35 & 96.24 & 95.95 \\
\hline 8 & 1.0 & $1: 10$ & 5 & 0.59 & 0.60 & 944.79 & 969.17 & 96.47 & 96.60 \\
\hline 9 & 1.0 & $1: 15$ & 7 & 0.3 & 0.39 & 817.27 & 815.35 & 95.99 & 95.95 \\
\hline 10 & 1.0 & $1: 20$ & 5 & 0.7 & 0.61 & 906.37 & 881.36 & 95.73 & 95.61 \\
\hline 11 & 0.5 & $1: 20$ & 7 & 0.1 & 0.31 & 814.14 & 868.81 & 95.79 & 96.24 \\
\hline 12 & 1.5 & $1: 15$ & 9 & 0.59 & 0.71 & 809.84 & 839.20 & 96.34 & 96.67 \\
\hline 13 & 0.5 & $1: 15$ & 5 & 0.8 & 0.67 & 947.46 & 918.09 & 97.16 & 96.82 \\
\hline 14 & 1.0 & $1: 20$ & 9 & 0.9 & 0.88 & 948.12 & 923.73 & 98.75 & 98.61 \\
\hline 15 & 1.5 & $1: 15$ & 5 & 0.1 & 0.29 & 807.56 & 837.57 & 93.83 & 94.14 \\
\hline 16 & 1.0 & $1: 15$ & 7 & 0.29 & 0.39 & 825.22 & 815.35 & 96.57 & 95.95 \\
\hline 17 & 0.5 & $1: 15$ & 9 & 0.79 & 0.59 & 893.33 & 863.31 & 96.11 & 95.79 \\
\hline
\end{tabular}



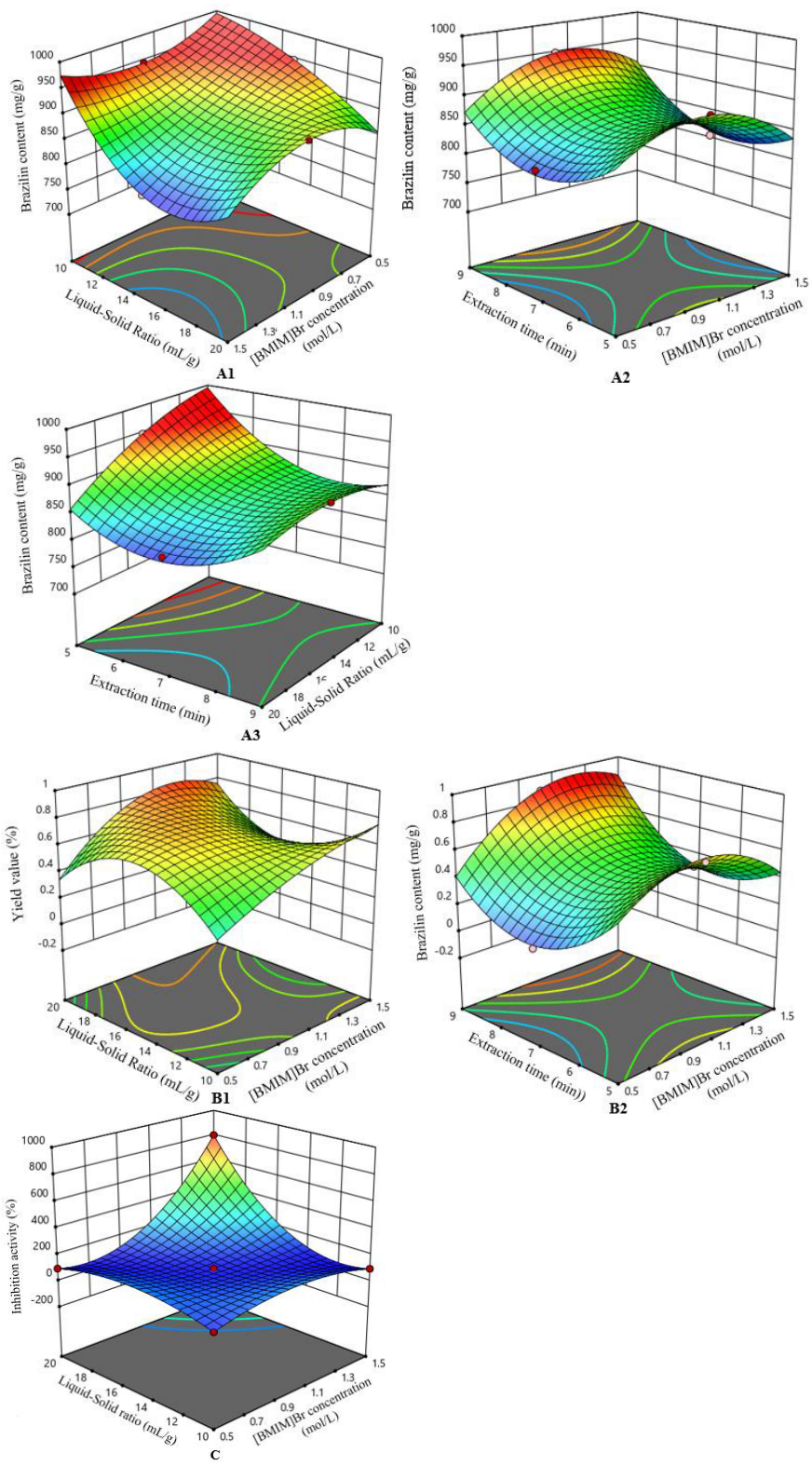

Figure 1. Three-dimensional response surface plot. Interaction of (A1) [BMIM] $\mathrm{Br}$ concentration and liquid-to-solid ratio, (A2) [BMIM] Br concentration and extraction time, and (A3) liquid-to-solid ratio and extraction time, against brazilin content; interaction of (B1) [BMIM]Br concentration and liquid-tosolid ratio and (B2) $[\mathrm{BMIM}] \mathrm{Br}$ concentration and extraction time, on yield value; and interaction of [BMIM] Br concentration and liquid- to-solid ratio on inhibition activity.

of $59,795.89$, meaning that the model is significant. $p$-values of $<0.0001$ (less than 0.0500 ) indicate that the model terms are significant, where $X_{1} X_{2}, X_{1}^{2}, X_{2}^{2}, X_{3}^{2}, X_{1}^{2} X_{2}$, and $X_{1} X_{2}^{2}$ are significant model terms in this condition.

The solid-to-liquid ratio is an essential factor in the extraction process, so a preoptimization process must be conducted to get the optimum condition (Mai et al., 2014). The HPLC analysis was conducted to determine the most optimum solid-toliquid ratio in extracting brazilin. Based on the HPLC analysis, a ratio of $1: 15 \mathrm{~g} / \mathrm{ml}$ was the most optimum solid-to-liquid ratio and used as 0 value in RSM design. The solid-to-liquid ratio affected
Table 3. ANOVA of yield value.

\begin{tabular}{cccccc}
\hline Source & Sum of squares & df & Mean square & $\boldsymbol{F}$-value & $\boldsymbol{p}$-value \\
\hline Model & 0.9471 & 8 & 0.1184 & 4.12 & 0.0308 \\
\hline$X_{1}$ & 0.2025 & 1 & 0.2025 & 7.04 & 0.0291 \\
$X_{2}$ & 0.0400 & 1 & 0.0400 & 1.39 & 0.2721 \\
$X_{3}$ & 0.0544 & 1 & 0.0544 & 1.89 & 0.2060 \\
$X_{1} X_{3}$ & 0.0625 & 1 & 0.0626 & 2.17 & 0.1786 \\
$X_{1}^{2}$ & 0.1099 & 1 & 0.1099 & 3.82 & 0.0863 \\
$X_{3}^{2}$ & 0.4631 & 1 & 0.4631 & 16.11 & 0.0039 \\
$X_{1}^{2} X_{2}$ & 0.0190 & 1 & 0.0190 & 0.6614 & 0.4396 \\
$X_{1} X_{2}^{2}$ & 0.2080 & 1 & 0.2080 & 7.24 & 0.0275 \\
Residual & 0.2300 & 8 & 0.0287 & & \\
Lack of fit & 0.0259 & 4 & 0.0065 & 0.1267 & 0.9649 \\
Pure error & 0.2041 & 4 & 0.0610 & & \\
Cor total & 1.18 & 16 & & & \\
\hline
\end{tabular}

Table 4. ANOVA of brazilin levels.

\begin{tabular}{cccccc}
\hline Source & $\begin{array}{c}\text { Sum of } \\
\text { squares }\end{array}$ & df & $\begin{array}{c}\text { Mean } \\
\text { square }\end{array}$ & $\boldsymbol{F}$-value & $\boldsymbol{p}$-value \\
\hline Model & $46,771.40$ & 10 & $4,677.14$ & 67.19 & $<0.0001$ \\
$X_{1}$ & $12,474.66$ & 1 & $12,474.66$ & 179.19 & $<0.0001$ \\
$X_{2}$ & 933.00 & 1 & 933.00 & 13.40 & 0.0106 \\
$X_{3}$ & $1,412.20$ & 1 & $1,412.20$ & 20.29 & 0.0041 \\
$X_{1} X_{3}$ & 795.24 & 1 & 795.24 & 11.42 & 0.0149 \\
$X_{2} X_{3}$ & $4,756.17$ & 1 & $4,756.17$ & 68.32 & 0.0002 \\
$X_{1}^{2}$ & 373.98 & 1 & 373.98 & 5.37 & 0.0596 \\
$X_{2}^{2}$ & $6,079.36$ & 1 & $6,079.36$ & 87.33 & $<0.0001$ \\
$X_{3}^{2}$ & $14,468.90$ & 1 & $14,468.90$ & 207.84 & $<0.0001$ \\
$X_{1}^{2} X_{2}$ & $4,898.52$ & 1 & $4,898.52$ & 70.37 & 0.0002 \\
$X_{1} X_{2}^{2}$ & $7,066.82$ & 1 & $7,066.82$ & 101.51 & $<0.0001$ \\
Residual & 417.69 & 6 & 69.62 & & \\
Lack of fit & 258.59 & 2 & 129.29 & 3.25 & 0.1451 \\
Pure error & 159.10 & 4 & 39.78 & & \\
Cor total & $47,189.09$ & 16 & & & \\
\hline
\end{tabular}

extraction efficiency. The large solvent volume can increase extraction value, increase the number of extractants and extractor capacity, and facilitate the extracted target compounds. On the contrary, smaller volumes of solvents allow for the withdrawal of incomplete molecules in the extraction process (Fadhila et al., 2018; Mai et al., 2014).

HPLC analysis showed that extraction efficiency increases with increasing concentration and reaches optimum concentration at $1 \mathrm{~mol} / \mathrm{l}$; the concentration after that decreases and is constant. Extraction efficiency increases with increasing concentration and reaches an optimum concentration of $1 \mathrm{~mol} / \mathrm{l}$; the concentration then decreases and is constant. It can be explained that a large number of micelles are formed with the addition of IL concentrations. IL produces stronger interactions with flavonoids by hydrogen bonds and forces between molecules, increasing relative extraction efficiency. On the other hand, an increasing IL concentration affects increasing viscosity and diffusion resistance, making the IL more challenging to penetrate the herbal matrix. 
Table 5. ANOVA of inhibition activity.

\begin{tabular}{cccccc}
\hline Source & $\begin{array}{c}\text { Sum of } \\
\text { squares }\end{array}$ & df & $\begin{array}{c}\text { Mean } \\
\text { square }\end{array}$ & $\boldsymbol{F}$-value & $\boldsymbol{p}$-value \\
\hline Model & 467.000 & 9 & $51,892.22$ & $59,795.89$ & $<0.0001$ \\
$X_{1}$ & 2.40 & 1 & 2.40 & 179.19 & $<0.0001$ \\
$X_{2}$ & 2.42 & 1 & 2.42 & 13.40 & 0.0106 \\
$X_{3}$ & 1.06 & 1 & 1.06 & 20.29 & 0.0041 \\
$X_{1} X_{2}$ & 123.500 & 1 & 123.500 & 5.37 & 0.0596 \\
$X_{1}^{2}$ & $31,796.80$ & 1 & $31,796.80$ & $36,639.75$ & $<0.0001$ \\
$X_{2}^{2}$ & $32,608.72$ & 1 & $32,608.72$ & $37,575.34$ & $<0.0001$ \\
$X_{3}^{2}$ & $31,867.09$ & 1 & $31,867.09$ & $36,720.75$ & $<0.0001$ \\
$X_{1}^{2} X_{2}$ & $62,239.21$ & 1 & $62,239.21$ & $71,718.83$ & $<0.0001$ \\
$X_{1} X_{2}^{2}$ & $62,898.95$ & 1 & $62,898.95$ & $72,479.05$ & $<0.0001$ \\
Residual & 6.07 & 7 & 0.8678 & & \\
Lack of Fit & 4.85 & 3 & 1.62 & & \\
Pure Error & 1.23 & 4 & 0.3073 & 5.26 & 0.0714 \\
Cor total & 467.000 & 16 & & & \\
\hline
\end{tabular}

Table 6. Percent inhibition of DPP-IV and $\mathrm{IC}_{50}$ values.

\begin{tabular}{|c|c|c|c|}
\hline Inhibitor & $\begin{array}{c}\text { Concentration } \\
(\mathrm{ppm})\end{array}$ & $\begin{array}{c}\text { Percent } \\
\text { inhibition (\%) }\end{array}$ & $\begin{array}{c}\mathrm{IC}_{50} \text { value } \\
(\mu \mathrm{g} / \mathrm{ml})\end{array}$ \\
\hline \multirow[t]{6}{*}{ Sitagliptin } & 100 & 90.09 & 9.37 \\
\hline & 80 & 74.51 & \\
\hline & 40 & 60.21 & \\
\hline & 20 & 48.29 & \\
\hline & 10 & 44.25 & \\
\hline & 5 & 40.36 & \\
\hline \multirow[t]{6}{*}{ Brazilin standard } & 100 & 84.55 & 11.7 \\
\hline & 50 & 67.68 & \\
\hline & 25 & 65.23 & \\
\hline & 12.5 & 50.32 & \\
\hline & 6.25 & 44.45 & \\
\hline & 3.25 & 26.18 & \\
\hline \multirow{6}{*}{$\begin{array}{l}\text { Extract sample from } \\
\text { optimized extraction } \\
\text { condition }\end{array}$} & 100 & 93.14 & 16.35 \\
\hline & 50 & 72.44 & \\
\hline & 25 & 52.84 & \\
\hline & 12.5 & 34.59 & \\
\hline & 6.25 & 30.77 & \\
\hline & 3.25 & 25.46 & \\
\hline \multirow{6}{*}{$\begin{array}{l}\text { Tannin elimination's extract } \\
\text { sample }\end{array}$} & 100 & 83.26 & 22.15 \\
\hline & 50 & 70.05 & \\
\hline & 25 & 51.70 & \\
\hline & 12.5 & 29.56 & \\
\hline & 6.25 & 24.54 & \\
\hline & 3.25 & 12.22 & \\
\hline
\end{tabular}

Thus, extraction efficiency will decrease (Ayuningtyas et al., 2017).

Time affects extraction ability. Extended extraction times from 3 to 9 minutes can improve the effectiveness of extraction and better extract results. At the 9th minute, the maximum extraction has been reached (Svinyarov et al., 2016). Extraction becomes significant and increases yield value with a high power in a short time. A long time will cause the target compound's degradation due to excessive heat (Ballard et al., 2010). To avoid degradation and oxidation, it is imperative to choose the MAE time correctly, shorter than conventional techniques. Extended extraction times from 3 to 9 minutes can improve the effectivity of the extraction and better extract results, and at 9 minutes, the maximum extraction has been reached (Svinyarov et al., 2016). According to the RSM result, the analysis was obtained in IL-MAE's optimum condition including [BMIM] Br concentration of $1.5 \mathrm{~mol} / \mathrm{l}$, the solid-to-liquid ratio of $1: 20 \mathrm{~g} / \mathrm{ml}$, and extraction time of 9 minutes.

\section{Determination of brazilin in the extract by HPLC analysis}

The IL-MAE extraction method's yield ranged from $0.1 \%$ to $0.9 \%$, and the yield of the conventional extraction method was $18.29 \%$. Other pieces of literature stated the yield of sappan extract with the conventional extraction method was $21.7 \%$ (Ayuningtyas et al., 2017). The difference in yields in the IL-MAE extraction method is caused by the withdrawal of target compounds that have not been optimal in IL-MAE extraction. Furthermore, there may still be compounds left in IL solvents.

Higher brazilin levels of extraction using the IL-MAE method can be caused by the ability of ILs to increase the solubility of target compounds due to the presence of IL multi-interactions, mainly ionic and hydrogen bonds between imidazolium as cations and the target compounds. ILs can change the solution's dispersion factor and transfer energy from microwave energy waves to the sample. It affected the extraction efficiency and energy transfer rate according to ionic conduction heating (Kim et al., 2018).

The brazilin levels in 17 samples ranged from 807.56 to $948.12 \mathrm{mg} / \mathrm{g}$ extract, while based on previous research conducted by researchers, brazilin levels using conventional extraction methods were $907.93 \mathrm{mg} / \mathrm{g}$ extract. The various levels of brazilin are caused by the withdrawal of compounds from IL solvents that have not been optimal, so compounds are left in the IL phase. Based on a literature search, sappan extraction has never been found using the IL-MAE method.

The 14th sample with an IL concentration of $1 \mathrm{~mol} / \mathrm{l}$, solid-to-liquid ratio of 1:20 g/ml, and extraction time of 9 minutes showed that the brazilin levels were $948.12 \mathrm{mg} / \mathrm{g}$ extract. While the 13th sample showed that the brazilin levels were $947.46 \mathrm{mg} / \mathrm{g}$ extract, the results are not significantly different from the 14th sample. In both samples, there was no similar extraction condition. It can be concluded that there is no significant effect of extraction conditions on the levels of brazilin in the sample.

\section{DPP-IV activity assay}

DPP-IV activity test was carried out by the spectrofluorometry method using DPP-IV Activity Assay Kit (Cayman Chem). The highest percentage of inhibitory activity was $98.7 \%$, indicated by sample number 14 . Overall, all samples showed high inhibitory activity. Brazilin standard also showed high inhibitory activity at $84 \%$, whereas positive control of sitagliptin has an inhibitory activity of $90 \%$. The sappan extract extracted by conventional methods at $84.25 \%$ was DPP-IV inhibitory based on researchers' previous research. In comparison, the DPP-IV inhibition activity was extracted from sappan extracted by ILMAE method $>90 \%$. 
Elimination of tannins was conducted to eliminate the potency of bias. The sample with the highest inhibition percentage (sample number 14) was chosen as the tannin elimination sample. The percent inhibition of the sample was $83.25 \%$. Tannin affects extract inhibition activity of $\pm 15.65 \%$. Inhibition concentration of $50 \%\left(\mathrm{IC}_{50}\right)$ is the ability of the extract to provide $50 \%$ inhibition. Table 6 showed $\mathrm{IC}_{50}$ values for sitagliptin, brazilin standard, sample, and tannin elimination sample. The $\mathrm{IC}_{50}$ value for sitagliptin was $9.37 \mu \mathrm{g} / \mathrm{ml}$, brazilin standard was $11.7 \mu \mathrm{g} / \mathrm{ml}$, the sample was $16.35 \mu \mathrm{g} / \mathrm{ml}$, and tannin elimination's sample was $22.15 \mu \mathrm{g} / \mathrm{ml}$. It can be concluded that the inhibitory value by sappan extract cannot replace the positive sitagliptin control's value. However, based on these results, it is proved that sappan has potential DPPIV inhibitory activity, and the IL-MAE extraction method is able to increase the DPP-IV inhibitory activity of sappan extract.

Brazilin is a flavonoid compound. Flavonoids can generally bind to proteins and they can form enzyme-inhibitor bonds. However, this caused a decreasing enzyme activity, so the enzyme could not bind the substrate because the enzyme active site was occupied, and so the binding substrate becomes reduced.

Another possible mechanism for describing DPP-IV's inhibitory activity by sappan extract is the mechanism associated with insulin action. With insulin, brazilin in sappan extract can increase glucose lipogenesis and oxidation and increase enzymatic glucose metabolism processes. Brazilin decreases serine phosphorylation by increasing the insulin receptor function. Other studies have also reported that brazilin can stimulate glucose transport in vitro and reduce gluconeogenesis in diabetic rats. Brazilin is also known to inhibit aldose reductase activity.

\section{CONCLUSION}

In conclusion, based on the present study, imidazolium basic IL-MAE was optimized and first applied to elevate brazilin levels from sappan wood. After a preoptimization experiment, [BMIM]Br was chosen as the optimal basic IL. Based on the result of preoptimization (single-factor), these conditions were optimized using the Box-Behnken design. The optimum extraction conditions were obtained, including [BMIM] Br concentration of $1.5 \mathrm{~mol} / 1$, the solid-to-liquid ratio of $1: 20 \mathrm{~g} / \mathrm{ml}$, and an extraction time of 9 minutes. Sappan extract gives the in vitro inhibitory value of DPP-IV activity $>90 \%$.

\section{ACKNOWLEDGMENTS}

This study was financially supported by the Directorate of Research and Community Engagement (DRPM), Universitas Indonesia, via Hibah "Publikasi Terindeks Internasional (PUTI Q2)” grant number: NKB-4049/IN2.RST/HKP.05.00/2020.

\section{AUTHORS' CONTRIBUTIONS}

IA and EPS conducted the experiment, AEA and FCS conducted the DFT calculations, and IA and AM wrote and revised the manuscript. All authors agreed on the final version of this manuscript.

\section{CONFLICT OF INTEREST}

The authors state that thay have no conflict of interest.

\section{REFERENCES}

Ahmad I, Arifianti AE, Sakti AS, Saputri FC, Mun'im A. Simultaneous natural deep eutectic solvent-based compounds of cinnamon Bark ans sappan wood as a dipeptidyl peptidase IV inhibitor. Molecules, 2020a; 25(17): 3832-43.

Ahmad I, Elya B, Ismail YI, Noviani A, Kuncoro H, Maryono M, Ambarwati NSS. Design of ionic liquid-based microwave-assisted extraction of flavonoids from Cyclea barbata Miers. and its lipoxygenase inhibitory activity. J Appl Pharm Sci, 2020b; 10(4): 1-7.

Ahmad I, Yanuar A, Mulia K, Mun'im A. Ionic liquid-based microwave-assisted extraction: fast and green extraction method of secondary metabolites on medicinal plant. Pharmacogn Rev, 2018; 12(23):20-6.

Ahmad I, Yanuar A, Mulia K, Mun'im A. Optimization of ionic liquid-based microwave-assisted extraction of polyphenolic content from Peperomia pellucida (L) Kunth using response surface methodology. Asian Pac J Trop Biomed, 2017; 7(7):660-5.

Anderson JL, Ding J, Welton T, Armstrong DW. Characterizing ionic liquids on the basis of multiple solvation interactions. J Am Chem Soc, 2002; 26:14247-54.

Ayuningtyas I, Rahmawati M, Mun'im A. Optimization of ionic liquid-based microwave assisted extraction to obtain trans-resveratrol from Gnetum gnemon. J Young Pharm, 2017; 9(4):457-62.

Badami S, Geetha B, Sharma SV, Rajan S. Microwave-assisted rapid extraction of red dye from Caesalpinia sappan heartwood. Nat Prod Res, 2014; 21:37-41.

Ballard TS, Mallikarjunan P, Zhou K, Keefe SO. Microwaveassisted extraction of phenolic antioxidant compounds from peanut skins. Food Chem, 2010; 120(4):1185-92.

Chen $\mathrm{F}$, Hou $\mathrm{K}, \mathrm{Li} \mathrm{S}, \mathrm{Zu} \mathrm{Y}$, Yang $\mathrm{L}$. Extraction and chromatographic determination of shikimic acid in Chinese conifer needles with 1-benzyl-3-methylimidazolium bromide ionic liquid aqueous solutions. J Anal Methods Chem, 2014; 2014:256473.

Chen F, Zhang Q, Mo K, Fei S, Gu H, Yang L. Optimization of ionic liquid-based homogenate extraction of orientin and vitexin from the flowers of Trollius chinensis and its application on a pilot scale. Sep Purif Technol, 2017; 175:147-57.

Du F, Xiao X, Li G. Application of ionic liquids in the microwaveassisted extraction of trans-resveratrol from Rhizma Polygoni Cuspidati. J Chromatogr A, 2007; 1140:56-62.

Du F, Xiao X, Luo X, Li G. Application of ionic liquids in the microwave-assisted extraction of polyphenolic compounds from medicinal plants. Talanta, 2009; 78:1177-84.

Espino M, de los Angeles Fernandez M, Gomes FJV, Silva MF. Natural designer solvents for greening analytical chemistry. TrAC Trends Anal Chem, 2016; 76:126-36.

Fadhila M, Mun'im A, Jufri M. Ionic liquid-based microwaveassisted extraction (Il-MAE) of oxyresveratrol from Morus alba roots. J Appl Pharm Sci, 2018; 8(6):8-13.

Kim BR, Kim HY, Choi I, Kim JB, Han AR. DPP-IV inhibitory potential of flavonol glycosides isolated from the seeds of lens culinaris: in vitro and molecular docking analyses. Molecules, 2018; 23(8):1998.

Liu X, Huang X, Wang Y, Huang S, Lin X. Design and performance evaluation of ionic liquid-based microwave-assisted simultaneous extraction of kaempferol and quercetin from Chinese medicinal plants. Anal Methods, 2013; 5(10):2591-601.

Mai NL, Ahn K, Koo YM. Methods for recovery of ionic liquids-a review. Process Biochem, 2014; 49(5):872-81.

Nirmal NP, Rajput MS, Prasad RGSV, Ahmad M. Brazilin from Caesalpinia sappan heartwood and its pharmacological activities: a review. Asian Pac J Trop Med, 2015; 8(6):421-30.

Putri AM, Putri NB, Rachmaday R, Dilalah I, Murwanti R, Meiyanto E. Secang heartwood ethanolic extract (Caesalpinia sappan L.) inhibits mesenchymal stem cells senescence. Indones J Cancer Chemoprev, 2017; 8(3):119-26. 
Settharaksa S, Monton C, Pathompak P, Madaka F. HPLC method validation for determination of brazilin in Caesalpinia sappan $\mathrm{L}$. heartwood extract. Thai J Pharm Sci, 2017; 41:141-4.

Setyaningsih EP, Saputri FC, Mun'im A. The antidiabetic effectivity of Indonesian plant extracts via DPP-IV inhibitory mechanism. J Young Pharm, 2019; 11(2):161-4.

Svinyarov I, Keremedchieva R, Bogdanov M. Ionic liquidsupported solid-liquid extraction of bioactive alkaloids IV. New HPLC method for quantitative determination of galantamine in Leucojum aestivum L. (Amaryllidaceae). J Sep Sci Tech, 2016; 15(15-16):2691-9.

Tan Z, Yi Y, Wang H, Zhou W, Wang C, McPhee DJ. Extraction, preconcentration and isolation of flavonoids from Apocynum venetum $\mathrm{L}$. leaves using ionic liquid-based ultrasonic-assisted extraction coupled with an aqueous biphasic system. Molecules, 2016; 21(3):1-11.

Wei W, Fu YJ, Zu YG, Wang W, Luo M, Zhao CJ, Li CY, Zang L, Wei ZF. Ionic liquid-based microwave-assisted extraction for the determination of flavonoid glycosides in pigeon pea leaves by high-performance liquid chromatography-diode array detector with pentafluorophenyl column. J Sep Sci, 2012; 35(21):2875-83.

Xia Z, Li D, Li Q, Zhang Y, Kang W. Simultaneous determination of brazilin and protosappanin B in Caesalpinia sappan by ionic-liquid dispersive liquid-phase microextraction method combined with HPLC. Chem Central J, 2017; 11(114):1-11.

Xu W, Chu K, Li H, Zhang Y, Zheng H, Chen R, Chen L. Ionic liquid-based microwave-assisted extraction of flavonoids from Bauhinia championii (Benth.) Benth. Molecules, 2012; 17(12):14323-35.

Zhang Q, Zhao S, Chen J, Zhang L. Application of ionic liquid-based microwave-assisted extraction of flavonoids from Scutellaria baicalensis Georgi. J Chromatogr B, 2015; 1002:411-7.

How to cite this article:

Ahmad I, Setyaningsih EP, Arifianti AE, Saputri FC, Munim A. Optimization of ionic liquid-based microwave-assisted extraction on brazilin levels from sappan wood and its dipeptidyl peptidase IV inhibition activity. J Appl Pharm Sci, 2021; 11(07):072-079. 